\title{
A IDENTIDADE FEMININA À SOMBRA DA DOMINAÇÃO MASCULINA: UMA LEITURA DE CAMARÃO NO JANTAR, DE SONIA COUTINHO
}

\author{
THE FEMALE IDENTITY IN THE BORDER OF MALE DOMINATION: A \\ READING OF SHRIMP FOR DINNER, BY SONIA COUTINHO
}

Mírian Zafalon ${ }^{1}$

\begin{abstract}
RESUMO: Ainda que se viva, na contemporaneidade, um período de franca emancipação feminina, os conceitos de gênero continuam a ser questionados no sentido de desconstruir padrões arbitrários de comportamento androcêntrico e posturas femininas de submissão e resignação às estruturas de divisão sexual. Cada vez mais, as mulheres são convocadas a revelarem seus papéis sociais, buscando serem sujeitos em meio às complexas relações entre os sexos, rompendo com a eternização da violência simbólica. A construção de uma identidade faz parte deste processo de autoafirmação e permanência ativa das mulheres num contexto dominado, historicamente, pelos homens. Todavia, nem sempre as mulheres conseguem ultrapassar as barreiras de uma existência subordinada, para alcançarem real autonomia sobre suas vidas. Como é possível inferir por meio da leitura do conto Camarão no jantar, de Sonia Coutinho, a figura feminina, em momentos de carência afetiva e arroubos solitários, pode submeter-se aos caprichos masculinos, aceitando um perfil de invisibilidade que a relega a um plano hierarquicamente inferior, de subserviência e passividade. A análise atenta das relações de gênero indica que a dominação masculina pode construir-se sobre os pilares da fragilidade emotiva das mulheres, impedindo-as de assumir uma identidade autêntica, tornando-as reféns da parca atenção de seus dominadores.
\end{abstract}

PALAVRAS-CHAVE: Dominação masculina. Identidade. Relações de Gênero. Camarão no jantar.

ABSTRACT: Even if living, in contemporary times, a period of overt female emancipation, the gender concepts continue to be questioned in order to deconstruct arbitrary patterns of androcentric behavior and attitudes of female submission and resignation to the structures of gender division. Increasingly, women are called to reveal their social roles, seeking to be the subjects among the complex relationships between the sexes, breaking with the perpetuation of symbolic violence. The construction of an identity is a part of this self-assertion and remains of active women in a context dominated, historically, by men. However, not all women are able to overcome the barriers of a subordinate existence to achieve real autonomy over their lives. As it is possible to infer by reading the tale in Shrimp for dinner, by Sonia Coutinho, the female figure, in moments of affection privation and lonely overjoy, may submit to male whims, accepting a profile of invisibility that relegates a hierarchically inferior plan, of subservience and passivity. A careful analysis of gender relations indicates that male

${ }^{1}$ Doutoranda em Letras - Estudos Literários pelo Programa de Pós-Graduação em Letras - PLE, da Universidade Estadual de Maringá - UEM. E-mail: mzafalon@ bol.com.br 
domination can build up on the pillars of women emotional weakness, preventing them from taking a real identity, making them hostages to the scanty attention from their rulers.

KEYWORDS: Male Domination. Identity. Gender Relations. Shrimp for dinner. Introdução

Sabe-se que até a década de 60, a ideia sobre sexo biológico sempre foi abordada como uma questão ligada à natureza. Diante disso, os conceitos de feminino e masculino, fixando-se sobre a natureza, ultrapassavam seus limites. Neste contexto, as noções de gênero encontravam-se identificadas à cultura, às construções cristalizadas. Com as manifestações feministas e uma série de estudos acerca da relação entre os sexos, começou-se a debater e a desconstruir o maior problema dos gêneros: a hierarquização em virtude do poder, tradicionalmente, atribuído ao sexo masculino. Sobre isso, comenta Campos:

\begin{abstract}
Assim entendidos, os sistemas gênero-sexo historicamente realizados revelariam, na relação masculino e feminino, a opressão e exploração deste último pelo primeiro: a história das sociedades até agora existentes constituiria uma história da subordinação das mulheres pelos homens em base aos sistemas gênero-sexo que culturalmente produziram. (CAMPOS, 1992, p. 111).
\end{abstract}

Referenciando a estratificação arbitrária dos gêneros e a propósito de sua experiência com a nação cabila, Pierre Bourdieu (2005) traça o panorama da dominação masculina que se estabelece desde tempos imemoriais, argumentando que tal organização social persiste no mundo contemporâneo, embora de forma fragmentada e não mais em sua unidade conforme a tradição cultural da Cabília. A sociedade pesquisada por Bourdieu construiu uma divisão de atividades (sexuais, no trabalho, etc) entre homens e mulheres baseada em oposições binárias, ratificando tais separações pela incidência de determinantes histórico-sociais e culturais que regem a vida na comunidade.

Contra os hábitos cristalizados pela tradição patriarcal, encontra-se, do outro lado desta polêmica ordem social, um contexto novo e atual no qual não há dúvidas de que as mulheres se encontram "em quase todas as profissões, que ocupem dinamicamente os múltiplos espaços da vida social e que circulem pelas ruas da cidade com toda desenvoltura, determinando decididamente os rumos das próprias vidas." 
(RAGO, 1996, p. 11). Toda esta projeção social, que muito deve aos movimentos feministas propagados desde o começo do século XX, no entanto, ainda não trouxe total estabilidade à trajetória feminina no cenário histórico-social, uma vez que as relações entre os sexos permanecem com pontos de obscuridade em muitas situações da vida diária. Embora a incidência de um padrão masculino machista seja, em grande parte dos casos, o motivo para a negação à liberdade plena de expressão e ação femininas, percebe-se que as próprias mulheres, conformadas à tradição, nem sempre conseguem prosseguir no seu intento de emancipação, abdicando de seus direitos para manterem-se fiéis à crença de que a felicidade conjugal e familiar depende exclusivamente de suas capacidades de manutenção do lar.

Em parte, a contradição apresentada se pauta numa questão muito particular dos nossos dias: a busca da identidade. Para Bauman $(2005$, p. 11) "A questão da identidade também está ligada ao colapso do Estado de bem-estar social e ao posterior crescimento da sensação de insegurança, com a 'corrosão do caráter' que a insegurança e a flexibilidade no local de trabalho têm provocado na sociedade." O mundo contemporâneo desperta no ser humano a ansiedade por estabelecer níveis de comportamento que se adaptem ao seu tempo e à sua sociedade, formando uma identidade flexível e múltipla, a chamada identidade "líquida", cuja existência se explica em virtude da transitoriedade do contexto. Bauman ainda afirma que discutir identidade é analisar as escolhas que os indivíduos fazem, o caminho para o qual se direcionam e as mudanças de atitudes que demonstram no decorrer de suas existências, em prol de um "pertencimento". Quando se observa o comportamento de muitas mulheres em suas bases sociais e, especialmente, nas relações familiares e conjugais, pode-se perceber que a ideia de pertencimento é essencial para que defendam e utilizem determinadas posturas, especialmente no que diz respeito à submissão. Para sentirem-se aceitas, "normais", muitas vezes abdicam do papel de sujeito, tornando-se obedientes a uma imagem que as mantêm no grupo a que querem (precisam) pertencer. A instituição do casamento, portanto, gera uma noção de pertencimento que faz com que muitas mulheres não se sintam "deslocadas", ou até mesmo fragmentadas. Com isso, a mulher constrói uma identidade que a naturaliza diante do meio em que vive, instaurando o seu lócus, além de atender aos seus anseios pessoais. 
Em outra extremidade do debate, encontra-se a obra $O$ mundo das mulheres, na qual Alain Touraine relata as experiências de mulheres que foram entrevistadas para sua pesquisa, com o intuito de comprovar que o que se diz a respeito delas é diferente do que elas dizem e pensam sobre si. Para o pesquisador, o trabalho que executou prima por "[...] contribuir na redescoberta das mulheres como atrizes sociais - em revelando seus objetivos, os conflitos nos quais estão implicadas e a vontade de ser 'sujeitos' de suas próprias existências." (TOURAINE, 2007, p. 10). O autor assevera que as mulheres foram e ainda têm sido retratadas e compreendidas, em muitos estudos, como seres inferiores, cuja feminilidade é construída socialmente, caracterizadas por termos que revelam a dominação masculina superior às categorias de gênero. O feminismo se afirma então, nos primeiros tempos, como recusa ao pensamento de mulher como sexo frágil, cuja principal teoria:

[...] denuncia o poder do homem sobre a mulher, poder entendido como dominação da classe masculina sobre a classe feminina. Exalta-se a mulher como 'o proletário' do homem, ou seu colonizado, metáforas que haviam permitido às últimas gerações marxistas, ainda muito ativas depois dos anos sessenta, proclamar a unidade de todas as lutas e reduzir o combate das mulheres a simples organização de uma 'frente de mulheres' na batalha contra o capitalismo mundial. (TOURAINE, 2007, p. 16).

Esta discussão foi aprofundada, posteriormente, trazendo novas formulações sobre o lugar da mulher, criticando a dominação masculina como forma de controle social. Touraine, citando Butler, explica a verdadeira identidade elementar a qual a classe feminina busca:

Judith Butler nos convida a assumir a 'genealogia', tal como ela por primeiro a definiu: a identidade feminina, longe de ser um fato primeiro, é uma interiorização, jamais completamente alcançada, desta oposição binária entre homens e mulheres através da qual o homem fundou seu poder cultural e social sobre a mulher-natureza. (TOURAINE, 2007, p. 17).

Graças a Butler e a outras feministas a mobilização contra a dominação masculina ocupa espaço em vários lugares onde há, na contemporaneidade, repressão à mulher e desigualdade entre os sexos. Entretanto, o papel de mulher-vítima não é pertinente e nem propício para rechaçar as discriminações e violências contra as mulheres, uma vez que vitimizá-las, fazendo-as parecer mais frágeis do que realmente são, reitera a hegemonia masculina. Quando as mulheres aceitam o posto de vítimas da 
situação, injustiçadas pelos desmandos masculinos, são capazes de abrir mão de sua autonomia e emancipação, movidas pela ideia de uma "natureza feminina".

Contra a dominação e a vitimização surge a ideia pós-moderna de desconstrução das perspectivas de identidade, destacando-se a subjetividade feminina em detrimento dos conceitos essencialistas de sujeito. Hall (2009) potencializa o conceito de "identificação" para delinear a conceituação de identidade. Segundo o autor:

\begin{abstract}
Em contraste com o 'naturalismo' dessa definição, a abordagem discursiva vê a identificação como uma construção, como um processo nunca completado - como algo sempre 'em processo'. [...] A identificação é, pois, um processo de articulação, uma suturação, uma sobredeterminação, e não uma subsunção. Há sempre 'demasiado' ou 'muito pouco' - uma sobredeterminação ou uma falta, mas nunca um ajuste completo, uma totalidade. (HALL, 2009, p. 108).
\end{abstract}

Percebe-se que a identidade é um fator construído paulatinamente, no interior do discurso e que obedece a hierarquia de poder. Sendo assim, o discurso androcêntrico produz um sentido específico para os gêneros, solidificando a divisão sexual do trabalho, estabelecendo diferenças que são "naturalizadas" arbitrariamente. A identidade feminina é constituída, portanto, a partir do ato de liderança e dominação do homem, conferindo à mulher, como resultado, a exclusão.

Atento aos modelos dominantes de constituição da sociedade, o feminismo questionou e continua criticando o modo como a produção do conhecimento têm se instaurado; neste sentido, a política feminista faz tentativas para uma ruptura dos padrões tradicionais, em prol de uma proposta emancipadora do gênero feminino. Expõe Rago (1998, p. 5)

É na luta pela visibilidade da 'questão feminina', pela conquista e ampliação dos seus direitos específicos, pelo fortalecimento da identidade da mulher, que nasce um contradiscurso feminista e que se constitui um campo feminista do conhecimento. É a partir de uma luta política que nasce uma linguagem feminista. (Grifos da autora).

Por intermédio dos autores examinados até o momento, é possível delinear um cenário sintomático das relações entre os gêneros, construindo perspectivas sobre o padrão feminino de atuação na sociedade. Bourdieu (2005) analisa a dominação masculina como um fato naturalizado e solidificado socialmente, mas que tem sido questionado e desconstruído pelas últimas gerações de mulheres e homens que não 
compactuam com o pensamento de que "naturalmente" a classe feminina deve ser submetida e subjugada diante do poderio androcêntrico. Para Touraine (2007), as mulheres mostram-se muito mais autênticas e sedentas de independência do que parece em alguns estudos. Dialogando com Bourdieu, o autor reconhece que a construção do eu feminino passa pela imposição da dominação masculina, impedindo as mulheres de terem autonomia nas transformações de sua existência. Já a identidade humana, segundo o pensamento de Bauman (2005), é ancorada numa multiplicidade de escolhas, fato que pode levar a criar mais de uma identidade para a mesma pessoa e para as diferentes situações vividas. Bauman contrapõe identidade escolhida à identidade imposta, explicando que o indivíduo pode estar em permanente dúvida, flutuando em meio às vicissitudes do "ser" e do "querer ser". Hall (2009) afirma que a identidade é construída no discurso e, portanto, o fato do feminino ser dominado pelo masculino se dá por uma linguagem que naturaliza a prevalência de um dos sexos sobre o outro. As lutas e conquistas feministas, comentadas por Rago (1996), motivaram uma substancial mudança nas relações entre os sexos, fortalecendo a identidade feminina, mas ainda não são suficientes para uma equiparação entre os gêneros. É ponto pacífico que as mulheres querem autonomia e igualdade de direitos em todos os setores da sociedade e da vida pessoal. Para tanto, é preciso debater a desconstrução da dominação e a construção de uma identidade feminina livre dos preconceitos e da intolerância.

\section{Dominação e amor $x$ construção da identidade feminina}

As relações de dominação masculina podem ser observadas por meio de diferentes situações. Num nível mais visível e agressivo, encontra-se a subjugação feminina no espaço público, através da desigualdade de direitos trabalhistas; também se demonstra a força da dominação no ambiente privado, por meio da violência no casamento, do assédio moral e sexual. Mas há inúmeras formas, extremamente veladas, que também revelam o controle masculino, enfatizando que

A estrutura da dominação masculina é o princípio último dessas inúmeras relações de dominação/submissão singulares que, diferentes em sua forma segundo a posição, no espaço social, dos agentes envolvidos (diferenças às vezes enormes e visíveis; outras vezes infinitesimais e quase invisíveis, mas homólogas e unidas, por isso mesmo, por um ar de família) separam e unem, em cada um dos universos sociais, os homens e as mulheres, mantendo assim 
entre eles a 'linha mística' de que falava Virginia Woolf. (BOURDIEU, 2005, p. 127).

A dominação masculina, portanto, pode ser o produto tanto das demonstrações visíveis e taxativas de autoritarismo e poder, quanto da violência simbólica (invisível, suave) exercida pelas vias do discurso, da ânsia pelo pertencimento e pelas razões do sentimento. Esta dominação "simbólica" tem a especificidade de não parecer o que realmente é: a construção de um poder forte, real, sob a capa de uma relação natural entre os gêneros.

Historicizando o processo de dominação, Bourdieu (2005) alerta para a ideia de que a feminilidade da mulher é um fato pressuposto pela sociedade e tal característica faz dela um ser "para o outro". Sendo assim, trata-se de convencionar que o ser feminino foi criado para suprir as necessidades do ser masculino, sujeitando-se à ordem social de preeminência androcêntrica absoluta.

Para o antropólogo francês, o amor faz com que a dominação pareça "razoável”, ou até mesmo, invisível; sob esta ótica, o amor é a aceitação da dominação. O amor seria, assim, a chave para uma série de "milagres" que podem restabelecer uma nova ordem entre homens e mulheres: o milagre da não-violência; o milagre do reconhecimento mútuo, o milagre do desinteresse (amar é fazer o outro feliz). O misterioso sentimento do amor, retratado, principalmente, pela tradição literária, visto por um foco antropológico, pode ser entendido como um estado de fusão (um "perderse" no outro), que faz com que o sujeito abdique da intenção de dominar em prol de seu "reconhecimento". A necessidade de ser aceito e de pertencer a um polo, transforma o sentimento do amor numa possibilidade de integração, conferindo ao ser feminino uma identidade (e também identificação) com o habitus que está posto. De acordo com Zygmunt Bauman:

O anseio por identidade vem do desejo de segurança, ele próprio um sentimento ambíguo. Embora possa parecer estimulante num curto prazo, cheio de promessas e premonições vagas de uma experiência ainda não vivenciada, flutuar sem apoio num espaço pouco definido, num lugar teimosamente, pertubadoramente, 'nem-um-nem-outro', torna-se a longo prazo uma condição enervante e produtora de ansiedade. Por outro lado, uma posição fixa dentro uma infinidade de possibilidades também não é uma perspectiva atraente. (BAUMAN, 2005, p. 35). 
Para construir uma identidade que lhe dê reconhecimento, que a faça pertencer a um grupo, a mulher é motivada a seguir os caminhos do sentimento, do amor, à procura desta possível estabilidade socioemocional. Embora o indivíduo hodierno seja caracterizado como um ser livre, flutuante e flexível às mudanças, observa-se que quando se trata das relações entre os gêneros, a mulher, historicamente afetada pelo domínio do patriarcado, pode ser levada a renunciar ao direito de ser emancipada, perseguindo o mito da identidade fixa, seguindo os padrões socialmente aceitos. Para este tipo de mulher, sentir-se enleada aos fios do sentimento amoroso representa uma garantia de dissipar a ansiedade própria do lugar "nem-um-nem-outro", para o qual o mundo contemporâneo empurra.

Pode-se inferir que a busca pela afetividade constitui um porto seguro, que desresponsabiliza a mulher em relação ao sucesso no ambiente público. Por outro lado, aquelas que se notabilizaram fora do cenário doméstico, ainda hoje são rotuladas como incapazes de obter harmonia na vida pessoal:

\begin{abstract}
A verdade das relações estruturais de dominação sexual se deixa realmente entrever a partir do momento em que observamos, por exemplo, que as mulheres que atingiram os mais altos cargos (chefe, diretora em um ministério etc.) têm que 'pagar', de certo modo, por este sucesso profissional com um menor 'sucesso' na ordem doméstica (divórcio, casamento tardio, celibato, dificuldades ou fracassos como os filhos etc.) e na economia de bens simbólicos; ou, ao contrário, que o sucesso na empresa doméstica tem muitas vezes por contrapartida uma renúncia parcial ou total a maior sucesso profissional [...]. (BOURDIEU, 2005, p. 126).
\end{abstract}

A contradição construída a partir deste processo dialético concede uma ampla visão a respeito das regras para a conduta feminina, controlada pelo universo androcêntrico. O domínio masculino tem se eternizado por meio do patriarcado, ostentando o poder do homem em detrimento da proteção aos direitos das mulheres, em todas as áreas e instituições sociais. Ainda que as mulheres alcancem sucesso no mundo público, não são consideradas como "completas" se não apresentarem uma vida privada feliz. Para enfraquecer a manutenção da dominação masculina e dar propulsão à identidade emancipadora das mulheres, a antinomia independência feminina $\mathrm{X}$ infelicidade pessoal/subordinação deve ser desfeita. Só assim a unidade feminina poderá alcançar a mobilidade que permitirá a formação de uma identidade desejada, que possa flutuar entre os mundos privado e público, sem causar rupturas radicais ou controvérsias com nenhum dos dois espaços. 
A literatura de autoria feminina tem papel basilar para o debate sobre a desconstrução dos padrões de dominação e formação da identidade feminina, subvertendo a ordem tradicional da construção dos gêneros. Segundo Lauretis (1994), a estrutura dos gêneros se dá através do processo de representação e de autorrepresentação que envolve as ações e discursos masculinos e femininos. Sobretudo, os textos de autoria feminina buscam revelar a construção que as próprias mulheres fazem de si, resistindo à fragmentação de suas identidades.

\section{Sonia Coutinho: a problemática feminina no mundo contemporâneo}

A década de 1960 promoveu uma extensa conscientização sobre a independência da mulher, principalmente em virtude dos movimentos feministas atuantes neste período. Esse contexto propiciou o questionamento da situação feminina no interior da sociedade patriarcal, discutindo o papel de submissão investido à mulher. A partir dos fatos relatados, começou a emergir uma nova identidade feminina, em busca da emancipação e da igualdade de oportunidades e direitos. A literatura de autoria feminina floresceu com nomes como Nélida Piñon, Helena Parente Cunha, Lygia Fagundes Telles e Sonia Coutinho, reafirmando em sua prosa de ficção a necessidade de se repensar o perfil de mulher como sujeito social.

Esse contexto de amplas transformações culturais foi extremamente fértil para a escrita de Sonia Coutinho (1939-2013). A autora, nascida em Itabuna, foi jornalista, tradutora, contista e romancista e passou a destacar-se na literatura brasileira a partir de 1960. Seu primeiro livro, Do herói inútil, foi lançado em 1966. Dentre suas obras, podese destacar: Os venenos de Lucrécia (1978, contos) ganhador do prêmio Status de Literatura; O jogo de Ifá (1980, romance); Os seios de Pandora (1998, romance) vencedor do prêmio Jabuti; Mil olhos de uma rosa (2001, contos) e Ovelha Negra e Amiga Loura (2006, contos) vencedor do prêmio Clarice Lispector, da Biblioteca Nacional. Alguns de seus livros foram lançados nos Estados Unidos, França e Alemanha. É considerada pela crítica como um dos maiores expoentes da literatura de autoria feminina na época contemporânea.

As personagens de Sonia Coutinho, geralmente, são pessoas solitárias que não têm perspectivas de extrapolar seus contextos de melancolia. A autora dialoga com o 
cinema e com a música, com as teorias feministas e com a psicanálise, enredando suas personas no complexo debate sobre a existência humana, especialmente no tocante à construção do eu feminino. A escritora baiana utiliza várias ligações intertextuais, retomando a história e a cultura da sociedade em geral, construindo um universo ficcional no qual as personagens e conflitos suscitam questões sobre os papéis sociais ocupados por homens e mulheres, debatendo a representação feminina e ressignificando sua postura, tradicionalmente, submissa.

Temas como a emancipação feminina, a busca da identidade, a liberação sexual, o autoconhecimento e a solidão são recorrentes na obra desta autora, apresentando as dificuldades que a mulher da atualidade enfrenta nas relações entre os sexos. As personagens femininas estão envolvidas em questões afetivas e familiares para as quais não encontram uma solução, embora representem uma geração que alcançou avanços na área social e sexual. A obra Mil olhos de uma rosa, na qual se encontra o conto que será analisado neste artigo, é uma produção que prioriza personagens solitárias, mulheres que buscam a autonomia e a inversão dos valores que sempre opuseram masculino a feminino, mas que mergulham na angústia de uma existência infeliz e vazia.

\section{Camarão no jantar: a anulação do "eu" feminino}

O enredo do conto Camarão no jantar pode ser sintetizado da seguinte forma: uma mulher solitária e carente resolve preparar um jantar especial para o homem que ama e que não vê há algum tempo. Enquanto faz os preparativos para a noite esperada, desperta suas reminiscências, relembrando toda a trajetória deste caso de amor. O amado, cujo nome é Rogério, não comparece ao jantar, embora houvesse prometido ir, e logo depois desaparece da vida da mulher, sem deixar qualquer contato. Passam tempos, anos e ela não o esquece, sentindo-se conformada à dor da perda.

A narrativa do conto divide-se em três partes que aparecem demarcadas graficamente. Na primeira parte, a personagem central desenvolve o seu plano de reconquista do antigo amor, faz a preparação para a noite do jantar e todo o histórico do relacionamento do casal é relatado. Na segunda parte, bastante curta, é descrita a espera e a decepção da protagonista, na noite ansiosamente aguardada. A terceira e última parte 
mostra que, apesar de já ter passado muito tempo, a personagem ainda alimenta vagas esperanças de reencontrar o homem amado e continua a sofrer por ele.

Narra-se o texto em terceira pessoa, por meio de um narrador que descreve todos os estados de alma da personagem central, situando o leitor na complexa e angustiada existência de uma mulher mal resolvida e mal-amada. $\mathrm{O}$ texto percorre as vias que conduzem à ideia de dominação masculina e que produzem o achatamento de qualquer possibilidade de emancipação. Percebe-se, desde as primeiras linhas do conto, que a figura feminina é relegada a segundo plano, inclusive não tendo seu nome mencionado. A personagem masculina, esta sim é nomeada várias vezes: Rogério. É possível inferir que este fato é sintomático para a hierarquização dos valores de cada uma das personagens; ele tem nome e é importante para ela, enquanto ela não é nomeada e também não tem importância para ele.

O primeiro parágrafo do texto apresenta a protagonista como uma pessoa que pensa em modificar afetivamente sua vida, por meio do retorno a uma antiga paixão: "Depois do café da manhã, achou que era preciso mudar tudo. Como? Ah, sim, grande ideia: tentar reativar um grande amor, que permanece em banho-maria. Morno mas ainda aquecido." (COUTINHO, 2001, p. 39). Na verdade, a mulher do conto figurativiza uma tentativa de emancipação, que mais à frente constatar-se-á, será frustrada. O resgate da paixão do passado é a possibilidade da mulher criar um vínculo de pertencimento, uma identidade que a faça ausentar-se de uma vida sem sentido, para dar razão efetiva para sua existência. Ela foge da "identidade da subclasse", assim descrita por Bauman:

O significado da 'identidade da subclasse' é a ausência de identidade, a abolição ou negação da individualidade, do 'rosto' - esse objeto do dever ético e da preocupação moral. Você é excluído do espaço social em que as identidades são buscadas, escolhidas, construídas, avaliadas, confirmadas ou refutadas. (BAUMAN, 2005, p. 46, grifo do autor).

A personagem do conto vive sozinha, mas mantém um envolvimento (anteriormente com frequência e, posteriormente, apenas eventual) com um homem casado, fato que a coloca numa situação desconfortável, diante de uma condição imoral para a sociedade: "A história era horrorosa: ele era casado desde quando se conheceram [...]." (COUTINHO, 2001, p. 40). Sobre ela recaem os preconceitos da ordem social, pois a mulher, na maior parte dos casos de relações extraconjugais, é culpabilizada e 
tomada como pivô da discórdia. A partir da descrição do "mito da origem" relatado na sociedade cabila, Bourdieu (2005, p. 29) ratifica a visão arbitrária que se faz sobre a mulher: “[...] iniciadora perversa, naturalmente instruída nas coisas do amor, [...]”.

Para fugir da solidão, a protagonista busca uma dependência na atenção e no afeto do homem amado, tentando amparar-se na expectativa do reconhecimento. Infelizmente, o sentimento não é recíproco, e mesmo as poucas migalhas de carinho acabam por lhe serem negadas. Ocorre uma mudança de identificação, que transforma uma mulher aparentemente livre, descolada, viajada "Ela que sempre fez um gênero 'alternativo', ela que usava bolsas indianas, colares artesanais, ela que anda com sujeitos mais para artistas, 'papo-cabeça'." (COUTINHO, 2001, p. 42), num ser submisso, cujas ações e pensamentos passam a ser determinados pelo poder masculino. Bauman explica que há dois grupos de identificação. Um deles é formado por indivíduos que constroem suas identidades conforme o seu próprio desejo. O outro se constitui de pessoas oprimidas por identidades impostas. Segundo o autor

\footnotetext{
A maioria de nós paira desconfortavelmente entre esses dois pólos, sem jamais ter certeza do tempo de duração de nossa liberdade de escolher o que desejamos e rejeitar o que nos desagrada, ou se seremos capazes de manter a posição de que atualmente desfrutamos pelo tempo que julgamos satisfatório e desejável. Na maior parte do tempo, o prazer de selecionar uma identidade estimulante é corrompido pelo medo. (BAUMAN, 2005, p. 44-45).
}

No caso da personagem do conto, o conflito de identidade a posiciona num “não-lugar”, no qual ela não significa uma referência importante para Rogério, mas também não consegue tornar-se independente desta relação, distanciando-se de possuir uma vida autêntica, uma vez que está presa aos laços de um amor sem futuro e sentindose culpada pelo fracasso da vida a dois:

Um amor que, no entanto, ela continua achando que não levou tão a sério quanto merecia. Por que teve aquela reação tão radical, quando soube que ele era casado? Por que não fez como as outras, foi levando? Como não percebeu na mesma hora que tinha de ser humilde, porque jamais esqueceria aquele amor? (COUTINHO, 2001, p. 43).

O conflito delineado no texto ficcional metaforiza as relações de gênero, marcando a ideologia reinante para homens e mulheres, sendo sua construção produto tanto da representação quanto da autorrepresentação. Tais representações demarcadas no texto mostram com clareza a figura do homem dominador e a supremacia masculina, 
sobretudo no que diz respeito à sexualidade. Rogério envolve-se, nitidamente, pelo prazer das relações físicas, enquanto a protagonista o ama além das sensações que o corpo pode causar. Este comportamento "naturalizado" pelo mundo androcêntrico, é relatado por Bourdieu:

À diferença das mulheres, que estão socialmente preparadas para viver a sexualidade como uma experiência íntima e fortemente carregada de afetividade, que não inclui necessariamente a penetração, mas que pode incluir um amplo leque de atividades (falar, tocar, acariciar, abraçar etc.), os rapazes tendem a 'compartimentar' a sexualidade, concebida como um ato agressivo, e sobretudo físico, de conquista orientada para a penetração e o orgasmo. (BOURDIEU, 2005, p. 30).

Quanto à divisão do trabalho entre o feminino e o masculino, observa-se que a personagem do conto é condicionada a assumir a função de mulher dona-de-casa para agradar ao homem. A autoridade masculina determina a função feminina, na medida em que a personagem assume a tarefa doméstica de cozinhar, tradicionalmente relegada à mulher como uma atividade inferior, menor. Concretiza-se, assim, a prática reproduzida pelo povo da Cabília:

[...] não exige da mulher mais que práticas técnicas ou rituais de acompanhamento, atos destinados a ajudar a natureza em trabalho (como arrancar ervas, ou reuni-las em feixes, para alimento dos animais); com este fato, elas estão duplamente condenadas a permanecer ignoradas, principalmente pelos homens: seus atos, familiares, contínuos, rotineiros, repetitivos e monótonos, 'humildes e fáceis', como diz nosso poeta, são em sua maior parte realizados fora da vista, na obscuridade da casa ou nos tempos mortos do ano agrário. (BOURDIEU, 2005, p. 59-60).

A narrativa confere ao homem, portanto, o status de ser superior, que mesmo afastado da personagem feminina, conduz os atos e os pensamentos dela. Trata-se de um poderoso dominador a quem ela exalta e enaltece em todos os momentos, submetendo-se a um relacionamento alicerçado sobre a mentira. Para ela, Rogério encarna a perfeição física, assemelhando-se a um deus grego, além de ser dotado do comportamento de um gentleman:

Que voz a dele, maravilhosa. E sua eterna gentileza.

Também engordou, como ela. Mas tem uma espécie de doçura que o torna lindo. Seus dedos... Aqueles dedos grandes. Um encanto irresistível que vem... sabe ela de onde!

Alto, todo grande, muito sério.

Um homem bem vestido e tratado como nunca tivera igual. (COUTINHO, 2001, p. 40-41). 
Este endeusamento potencializa a imponência de Rogério, exaltando seu magnetismo pessoal que é plenamente absorvido pela personagem feminina, naturalizando sua postura próxima de "escrava" em relação a ele. Por outro lado, o tom elogioso para com Rogério, a nuvem de qualificações que o envolve, obscurece seu real perfil: trata-se de um homem que não corresponde ao amor da mulher, dissimulado o suficiente para mantê-la ligada a ele, satisfazendo seu ego masculino. Ainda que ela reconheça as mentiras dele, saiba que ele roubou dos aluguéis de sua mãe e que tivesse sido rotulado como "trambiqueiro perigoso", ela persiste no seu amor e continua a sofrer por ele, demonstrando a impossibilidade de partir para outras relações, de buscar emancipação de sua vida e de seus sentimentos. O comportamento feminino no conto reforça a ideia de que a "violência simbólica" mantém o habitus de primazia dos homens sobre as mulheres. Segundo Bourdieu:

[...] as próprias mulheres aplicam a toda a realidade e, particularmente, às relações de poder em que se vêem envolvidas esquemas de pensamento que são produto da incorporação dessas relações de poder e que se expressam nas oposições fundantes da ordem simbólica. Por conseguinte, seus atos de conhecimento são, exatamente por isso, atos de reconhecimento prático, de adesão dóxica, crença que não tem que se pensar e se afirmar como tal e que 'faz', de certo modo, a violência simbólica que ela sofre. (BOURDIEU, 2005, p. 45).

Portanto, a protagonista compactua com a dominação masculina, abre mão de uma identidade liberada e independente, em prol de um amor não correspondido, mas que, de alguma maneira, preenche sua vida. Pode-se entrever que a imagem de mulher emancipada, que "Está acostumada a sair sozinha, a entrar nos restaurantes sem olhar em torno." (COUTINHO, 2001, p. 43) não passa de um simulacro. O verdadeiro perfil aponta para uma mulher insegura e carente, atraída por um homem muito diferente dos amigos dela, mas que a seduziu de maneira avassaladora. Obviamente, a protagonista não assume o papel de sujeito, deixando-se aprisionar pelos desmandos do par, sujeitando-se à situação de ser "a outra". No trecho "Até então tinha sido enganada - ou se enganara, voluntariamente em dois anos de relacionamento tórrido (de sua parte)" (COUTINHO, 2001, p. 39), que relata a descoberta de que Rogério era casado, percebese a submissão da mulher às falsas promessas e, além disso, a constatação de que ela não enxergava os fatos reais porque não queria vê-los. $\mathrm{O}$ "amour fou" sempre foi uma 
via de mão única, ou seja, ela jamais teve o retorno esperado, pois o sentimento não era equivalente para ambos. A solidão da qual a personagem se tornou refém é fruto da exacerbação do amor, mas também da desresponsabilização em vistas do sentimento, “amitié amoureuse", característica que enfatiza o amor, diluído em erotismo ocasional.

A angústia da protagonista também é marcada por meio da música que ela ouve nos seus piores momentos: o jazz. Sonia Coutinho faz referência a este estilo musical em vários de seus contos, como forma de construir uma identificação entre a expressão dolorosa do sofrer que a música evoca e a identidade conturbada e solitária de suas personagens. Na voz e na letra de Billie Holiday, sugere-se que se encontra o entendimento sobre o estado emocional da personagem, seu fracasso nas relações amorosas.

O sentimento de melancolia despertado pelo jazz não é o único a relatar o complexo de inferioridade constante na personagem. Historicamente, a mulher tem ocupado o segundo plano e o lugar passivo diante dos acontecimentos, abrindo mão de seu ímpeto para ceder ao poderio masculino. Acerca da crítica do feminismo à História, Rago diz:

Certamente, o feminismo coloca o dedo nesta ferida, mostrando que as mulheres foram e ainda têm sido esquecidas não só em suas reivindicações, em suas lutas, em seus direitos, mas em suas ações. Suprimidas da História, foram alocadas na figura da passividade, do silêncio, da sombra na esfera desvalorizada do privado. (RAGO, 1996, p. 15).

Na narrativa analisada, é nítida a anulação da personagem, a passividade que a leva a viver em função dos poucos momentos que pode ter, junto ao homem que deseja. Este tom de obediência faz lembrar as ideias que pairavam sobre as questões de gênero, no início do século XX, tão bem explicitadas na Revista Feminina (1917), parafraseada por Rago:

\begin{abstract}
A 'esposa perfeita' deveria preparar os pratos favoritos do marido, arranjar a mesa ao gosto dele, escolher a melhor cadeira e lugar para ele à mesa; criar as condições para que ele pudesse ler o jornal tranquilamente e, especialmente, não perturbá-lo sem motivo. [...] Em suma, a 'esposa perfeita' deveria anularse radicalmente em presença do marido, [...]. (RAGO, 1996, p. 25).
\end{abstract}

Tal como a esposa perfeita descrita pela Revista Feminina, a protagonista do conto esmera-se na arte de cozinhar, mesmo sem apreciar esta tarefa, para comprovar 
seus cuidados para com o amado; embora não seja a esposa dele, ela age com a docilidade e a passividade que considera serem necessárias a ele, buscando uma reciprocidade que jamais fora atingida. Entretanto, a arma mais efetiva da qual a personagem se utiliza para (re) conquistar o seu amor se refere ao corpo. No conto é possível perceber que este corpo e toda a sexualidade que estaria aliada a ele não são suficientes para que Rogério a ame como ela o ama. Em "Também engordou, como ela" (COUTINHO, 2001, p. 40), "Rogério era dez anos mais novo. O que dava àquele relacionamento o indispensável caráter de impossibilidade" (COUTINHO, 2001, p.42) e "No dia da descoberta, estava no escritório dele e entrou uma garota linda, com um casaco de couro preto... Sorria, sorria para Rogério" (COUTINHO, 2001, p.44), encontram-se três situações que dão ênfase, de modos diferentes, ao corpo, sempre colocando a protagonista no posto de preterida, em desvantagem. Infere-se que ela já não possui as mesmas formas corporais de quando se conheceram, vinte anos antes; acresce-se o fato de que ela é dez anos mais velha que ele e que Rogério não tem o perfil de homem fiel, portanto poderia já estar encantado por outra mulher, mais jovem e mais bonita. A protagonista tem plena consciência de que, com o passar do tempo, havia desmotivado o interesse daquele homem, passando a se sentir insegura em relação ao seu corpo, não possuindo autonomia para aceitar a si mesma. Conforme Bourdieu:

A dominação masculina, que constitui as mulheres como objetos simbólicos, cujo ser (esse) é um ser-percebido (percipi), tem por efeito colocá-las em permanente estado de insegurança corporal, ou melhor, de dependência simbólica: elas existem primeiro pelo, e para, o olhar dos outros, ou seja, enquanto objetos receptivos, ataentes, disponíveis. (BOURDIEU, 2005, p. 82 , grifo do autor).

O discurso narrativo de Sonia Coutinho corrobora o sentido de corpo como espaço de inscrição cultural, validando a desigualdade imposta socialmente ao ser feminino. Segundo Showalter (1994), o que se pensa a respeito do corpo é essencial para desvendar como as mulheres conceituam seu lugar social. Para a autoafirmação da personagem do conto, seria preciso que ela entendesse seu corpo, encontrando nele a verdadeira beleza, consoante explica Kehl, citada por Rago:

A maior beleza é a do corpo livre, desinibido em seu jeito próprio de ser, gracioso porque todo ser vivo é gracioso quando não vive oprimido e com medo. É a livre expressão de nossos humores, desejos e odores; é o fim da culpa e do medo que sentimos pela nossa sensualidade natural; e a conquista do direito e da coragem a uma vida afetiva mais satisfatória; é a liberdade, a 
ternura e a autoconfiança que nos tornarão belas. É essa a beleza fundamental. (KEHL, 1982 apud RAGO, 1996, p. 39).

Em suma, a personagem feminina do conto adere, de várias formas, ao poder do dominante, sendo vitimizada pela violência simbólica e naturalizando seu rebaixamento íntimo e social. A "dominada" mostra sua crença no modelo tradicional, que prega uma certa "vocação" das mulheres para "[...] as tarefas subordinadas ou subalternas que lhes são atribuídas por suas virtudes de submissão, de gentileza, de docilidade, de devotamento e de abnegação." (BOURDIEU, 2005, p. 73).

A protagonista representa uma vítima da dominação que contribuiu para que fosse dominada por meio de sua atitude passiva, por não mostrar independência da situação amorosa na qual se insere. Tem-se a impressão de que a personagem identificou-se com o sofrer, com a melancolia provocada pela falta de amor, traçando para si uma identidade vitimizada. O sentimento de amor promove, neste caso, a naturalização da dominação, privando a mulher de uma vivência autêntica e de relações profícuas, motivando sua existência sob a sombra de uma "hipótese" de vida a dois.

\section{Conclusão}

O histórico da dominação masculina tem sido desconstruído em função das lutas pela emancipação da mulher, sobretudo motivadas pelos movimentos feministas e pela produção artístico-literária do século XX. Paulatinamente, as mulheres têm ocupado os espaços públicos, passando a pertencer a um universo que, por muito tempo, foi de exclusividade masculina, construindo uma consciência de seu valor, opondo-se à pressão da sociedade androcêntrica. Embora se perceba um avanço significativo na postura da mulher no contexto sócio-cultural, ainda existe uma dependência afetiva e emocional intensa, fato que gera um desequilíbrio nas relações de gênero, levando muitas mulheres à subjugação.

A busca da identidade feminina, da autonomia, da independência financeira e do sucesso profissional também torna as mulheres mais vulneráveis, pois apesar de construírem uma projeção social, o preconceito é mantido, ainda que de forma velada, demarcando a hierarquia das posições masculinas e femininas. 
A dominação masculina apresenta uma dimensão sexualizada, evidenciada em todas as práticas sócio-culturais; mas também é na sexualidade que a aspiração à libertação das mulheres encontra suas bases para a criação da identidade. Consoante Touraine (2007), as mulheres reforçam a ordem social na qual elas dominam o espaço doméstico e os homens se sobrepõem no ambiente público. Tal comportamento demonstra que lutar pela liberação feminina não é o suficiente; é preciso haver consciência coletiva da situação da sociedade contemporânea, e adequação a esta nova realidade.

O conto Camarão no jantar traz uma discussão sobre as relações entre homens e mulheres, encarnando na personagem feminina a dominação irrestrita do homem. A protagonista se abstém do papel de sujeito, sendo objetificada pelo poder masculino, vivendo uma existência inautêntica em favor do sentimento amoroso. Por meio da escrita crítica e criativa de Sonia Coutinho, o leitor torna-se cúmplice da situação vivenciada pela personagem, buscando respostas para uma dominação que se pauta na carência afetiva da dominada, a qual parece contribuir para sua própria dominação, mantendo-se fiel a um amor não correspondido, numa tentativa desesperada de desfragmentar sua identidade.

A dominação masculina que ocorre no mundo da ficção leva a pensar que a construção dos gêneros e de suas relações é também a sua desconstrução. As representações de gênero atribuem sentido às posições sociais e, portanto, às posturas que lhe são concernentes. Desconstruir o gênero é, em suma, questionar os atributos que formaram, durante séculos, a constituição do masculino e do feminino, atribuindo à mulher sujeito a potencialidade de maximizar o seu valor, negando a opressão social e sexual, não aceitando a representação social que lhe é imposta.

\section{Referências}

BAUMAN, Zygmunt. Identidade - Entrevista a Benedetto Vecchi. Trad. Carlos Alberto Medeiros. Rio de Janeiro: Jorge Zahar Ed., 2005.

BOURDIEU, Pierre. A dominação masculina. Trad. Maria Helena Kühner. 4 ed. Rio de Janeiro: Bertrand Brasil, 2005.

CAMPOS, Maria Consuelo Cunha. Gênero. In: JOBIM, J. L. Palavras de crítica: tendências e conceitos no estudo da literatura. Rio de Janeiro: Imago, 1992. 
COUTINHO, Sonia. Mil olhos de uma rosa - contos. Rio de Janeiro: 7 letras, 2001. Disponível em: http://books.google.com.br/books?id=kUQ6993q6wEC\&pg=PA39\&lpg=PA39\&dq=ca mar\%C3\%A3o+no+jantar++sonia+coutinho\&source=bl\&ots=50fBGrEPsZ\&sig=gXm wOGW6FmGoPzFhjeZdf5KxU_4\&hl=ptBR\&sa=X\&ei=3d81UpHUDZLU9QTu94DA BQ\&ved=0CDIQ6AEwAQ\#v=onepage \&q=camar\%C3\%A3o\%20no\%20jantar\%20\%20sonia\%20coutinho\&f=false. Acesso em: 03 ago. 2014.

HALL, Stuart. Quem precisa da identidade? In: SILVA, Tomaz Tadeu da. (org.) Identidade e diferença - A perspectiva dos Estudos Culturais. Trad. Tomaz Tadeu da Silva. 9. Ed. Petrópolis, RJ: Vozes, 2009.

LAURETIS. Teresa de. A tecnologia do gênero. In: HOLLANDA, Heloísa Buarque. (Org.). Tendências e impasses: o feminismo como crítica da cultura. Rio de Janeiro: Rocco, 1994.

RAGO, Margareth. Adeus ao feminismo? Feminismo e (Pós) modernidade no Brasil. In: Cadernos do AEL: Mulher, História e Feminismo. N. 3-4. IFCH/UNICAMP, Campinas, 1995/1996. Disponível em: http://www.ael.ifch.unicamp.br/publicacoes ael/index.php/cadernos ael/article/viewFil e/151/152. Acesso em: 28 jul. 2014.

Epistemologia feminista, gênero e história. In: PEDRO, Joara; GROSSI, Miriam (Orgs.). Masculino, feminino, plural. Florianópolis: Ed. Mulheres, 1998.

SHOWALTER, Elaine. A crítica feminista no território selvagem. In: HOLLANDA, Heloísa

Buarque de (Org.). Tendências e impasses: o feminismo como crítica da cultura. Rio de Janeiro: Rocco, 1994.

TOURAINE, Alain. O mundo das mulheres. Trad. Francisco Morás. Petrópolis, RJ: Vozes, 2007. 